\title{
DILEMAS DA ORGANIZAÇÃO DO TRABALHO FACE A GLOBALIZAÇÃO E ÀS TECNOLOGIAS DE INFORMAÇÃO E COMUNICAÇÃO
}

\section{DILEMMAS OF WORK'S ORGANIZATION BEFORE GLOBALIZATION AND BEFORE THE TECHNOLOGIES OF INFORMATION AND COMMUNICATION}

JOSÉ MARIA CARVALHO FERREIRA

Professor titular e pesquisador do Instituto Superior de Economia e Gestão da Universidade Técnica de Lisboa. Rua Migue Lupi, 20, Lapa/Estrela - Lisboa - Portugal - CEP 1249-078

E-mail: jmcf@iseg.utl.pt 


\section{RESUMO}

Inscritas no contexto histórico da racionalidade instrumental do capitalismo, a crescente integração da ciência e da técnica tem-se traduzido num desenvolvimento exponencial das tecnologias de informação e de comunicação. Como denominador comum essencial, estas integram energia, informação e conhecimento que antes estavam integrados na acção individual e colectiva do factor de produção trabalho. Por outro lado, através dos seus efeitos estruturantes, a globalização, em termos sociais e espácio-temporais, tornou-se uma realidade cada vez mais plausível aos níveis local, regional, nacional e mundial. A plasticidade social desse processo é sobretudo visível ao nível das competências e qualificações que são exigidas ao factor de produção trabalho, mas também na estruturação de um novo modelo de produção, consumo, troca e distribuição de bens e serviços analíticosimbólicos. Do espaço-tempo da organização do trabalho emergem novas exigências e desafios em relação aos perfis profissionais, à execução de tarefas e funções, ao processo de liderança e ao processo de tomada de decisão. Como subsistemas primaciais de qualquer organização, indivíduos e grupos transformam-se progressivamente em processadores de energia, conhecimento e informação de bens e serviços analítico-simbólicos.

\section{PALAVRAS-CHA VE}

Tecnologias de informação e comunicação; Globalização; Divisão do trabalho; Processo de tomada de decisão; Processo de liderança.

\section{ABSTRACT}

Belonging to the historical context of the instrumental rationality of the capitalism, the growing integration of science and technique has been translated into an exponential growth of the technologies of information and communication. As an essential common denominator, these ones combine energy, information 
and knowledge, which used to be polarized in the individual and collective action of the production factor work. On another side, the globalization, through its structuring effects, has become a more and more visible reality, on social and time-space areas at all levels: local, regional, national and world level. The social plasticity of this process can be very well observed when you consider the required capacities and qualifications of the production factor work. You also can observe it, if you analyse the structure of a new model of production, consummation, change and distribution of analytic-symbolic goods and services. From the timespace of the work's organization emerge new demands and challenges, on what concerns the professional profiles, the accomplishment of tasks and functions, the process of leadership and the process of decision making. As main sub-systems of any organisation, individuals and groups progressively become energy, knowledge and information processors, only concerned on analytic-symbolic goods and services.

\section{KEYWORDS}

Technologies of information and communication; Globalization; Division of labour; Process of decision making; Process of leadership.

\section{INTRODUÇÃO EPISTEMOLÓGICA E METODOLÓGICA}

A pertinência científica da análise das contingências das tecnologias de informação e comunicação (TIC), assim como da globalização, em relação à organização do trabalho é deveras relevante. Nestes domínios, as mudanças em curso nas ciências sociais e humanas obrigam-nos a uma reflexão sem precedentes e com carácter imperativo.

O conceito central que me ajuda a interpretar e compreender essa realidade em transformação é o que denomino de racionalidade instrumental do capitalismo. A sua singularidade em termos de causas e efeitos sociais, económicos, políticos e culturais é de um valor heurístico indelével. É um factor estruturante de racionalização, assim como de institucionalização e formalização do factor de produção trabalho, enquanto meio ou instrumento crucial de maximização do lucro. Essa função, pelas suas interdependências e complementaridades, desenvolve-se de forma sistemática e profunda aos outros factores básicos da racionalidade instrumental do capitalismo: capital, terra e tecnologia. Como contingência da globalização, a racionalidade instrumental do capitalismo atravessa cada vez mais o espaço-tempo das actividades económicas circunscritas à produção, à dis- 
tribuição, à troca e ao consumo de bens e serviços. Como contingência das TIC, a crescente integração da ciência e da técnica potencia de uma forma inaudita as mudanças das competências e qualificações do factor de produção trabalho e, consequentemente, da sua eficácia e eficiência no contexto da racionalidade instrumental do capitalismo. Por sua vez, as contingências que acabámos de referir afectam sobremaneira o processo histórico de racionalização da organização do trabalho em termos de sua autoridade hierárquica formal, divisão do trabalho, processo de tomada de decisão e processo de liderança.

De uma forma sintética, em termos sociológicos, o conceito de racionalidade instrumental do capitalismo pode ser entendido como um processo de potenciação da eficácia da acção individual e colectiva do factor de produção, cuja plasticidade e finalidade social são deveras visíveis na produção, na distribuição, na troca e no consumo de bens e serviços de características imateriais. O factor de produção trabalho é a essência mercantil e produtiva da racionalidade instrumental do capitalismo, porque atravessa o espaço-tempo de todo esse processo e também porque é o único meio ou instrumento de maximização do lucro. Em qualquer contexto do espaço-tempo da sua evolução sócio-histórica, esteve sempre associado ao instrumento indelével da racionalidade instrumental do capitalismo, seja como factor trabalho, seja integrado em outros factores como a ciência, a técnica, a terra e o capital.

Qualquer um desses factores configura uma evolução histórica que culmina sempre na sua integração, interdependência e complementaridade sistemática. Desse facto, decorre a necessidade imperativa do seu desenvolvimento nos parâmetros da racionalidade instrumental do capitalismo, traduzindo-se sempre no aumento da sua utilidade e produtividade. Nessa assunção, a técnica e a ciência, desde os primórdios da Revolução Industrial na Inglaterra (MUMFORD, I934), integraram um processo de inovação em máquinas e ferramentas que originaram um aumento significativo dos índices de produtividade do factor de produção trabalho. No mesmo sentido, a crescente integração da ciência e da técnica traduziu-se na criação e inovação de máquinas-ferramentas, de novas energias e materiais que culminaram no desenvolvimento da capacidade produtiva e da rendibilidade das empresas capitalistas. Seguindo o mesmo raciocínio, podemos considerar o taylorismo e o fordismo (FERREIRA et al., 200I) como elementos potenciadores da racionalidade instrumental do capitalismo em relação à organização do trabalho.

A problemática do tempo sempre esteve associada a esse processo de racionalização, sobretudo como conceito de medida das interacções sociais directamente reportadas à redução dos gestos, dos movimentos e das pausas do factor de produção trabalho adstritas à execução de tarefas. Como meio ou instrumento da racionalidade instrumental do capitalismo, o tempo na sua materialização concre- 
ta funciona como uma variável quantitativa baseada no aumento dos índices de produtividade do factor de produção trabalho. Como factor cognitivo, emocional e físico incrustado na acção individual e colectiva expresso em formas de sentir, pensar e agir no âmbito da organização do trabalho, expressa-se qualitativamente em representações sociais (ELIAS, I998; BAUMAN, 200I). Neste sentido, a organização do trabalho sempre foi uma variável explicativa da melhoria das interacções do factor de produção trabalho com a técnica e a tecnologia, como também das transformações ocorridas na divisão do trabalho, na autoridade hierárquica formal, no processo de tomada de decisão e no processo de liderança.

Por sua vez, o processo de automatização e socialização da informação, do conhecimento e da energia traduziram-se numa desmaterialização profunda e sistemática dos inputs e outputs concernentes à produção, à distribuição, à troca e ao consumo de bens e serviços analítico-simbólicos. A coincidência do espaçotempo virtual com o espaço-tempo real destas actividades obrigou a uma reestruturação dos processos de codificação e de descodificação dos fluxos de informação, conhecimento e energia reportados a esses bens e serviços. Os actores individuais e colectivos, enquanto sistemas processadores de informação, conhecimento e energia concretos, são, cada vez mais, interdependentes e complementares, sendo, por esse facto, constrangidos a adaptar-se e a reagir a uma realidade cada vez mais abstracta e complexa. Os espaços-tempos das funções cognitivas, emocionais e energéticas desses actores não são mais de curto, médio ou longo prazos: na grande maioria dos casos são instantâneos e irrepetíveis. Para bens e serviços de carácter material deu-se uma redução drástica das temporalidades de sua produção, distribuição, troca e consumo. Todavia, no caso específico dos bens e serviços de natureza imaterial, estes são sujeitos à instantaneidade do presente, não sendo necessário transformar-se em réplicas mecânicas de um passado e um futuro inexistente.

A visibilidade social do que acabo referir é personificado pelas mudanças operadas na organização do trabalho, com especial incidência para a divisão do trabalho, a autoridade hierárquica formal, o processo de tomada de decisão e o processo de liderança de qualquer organização ou instituição das sociedades capitalistas mais desenvolvidas.

Para efeitos demonstrativos da evolução que acabo de referir, cingir-me-ei ao conhecimento empírico, para além da observação participante que tenho do modelo de organização do trabalho do sistema universitário português. Deste modo, em primeiro lugar, procurarei não só referir as contingências da globalização e das TIC em relação aos perfis profissionais dos três subsistemas fundamentais da organização do trabalho - professores, funcionários e estudantes -, mas também os problemas e desafios que estes actualmente defrontam nos domínios científico, pedagógico e organizacional. 


\section{TENDÊNCIAS E EFEITOS DA GLOBALIZAÇÃO E DAS NOVAS TECNOLOGIASS}

Não é objectivo desta análise comparar e desenvolver o conceito de globalização de uma forma sistemática e profunda. Todavia, podemos circunscrevermonos a uma síntese comparativa que nos aproxima da sua essência actual, tendo presentes os factores estruturantes que considero mais representativos.

Na opinião de alguns autores, a globalização revela-se um fenómeno histórico irreversível nos planos societal e civilizacional (SOROS, I999; ROBERTSON, 2000; WALLERSTEIN, I979; WATERS, 2002; BAUMAN, I999). Se pensarmos no objecto de observação do qual decorre a elaboração e originalidade probabilística do objecto científico, teremos que referir, impreterivelmente, os factores que atingirem maior plasticidade social em termos da sua profundidade e extensão.

Para nos ajudar a discernir sobre este dilema crucial, não podemos prescindir da análise das empresas transnacionais reportadas às actividades de produção, distribuição, troca e consumo de bens e serviços analítico-simbólicos. Sobre a amplitude desta evolução, basta-nos reportar à dimensão da população activa que integra o sector terciário dos países capitalistas mais desenvolvidos (BOLTANSKI; CHIAPELLO, I999; KERGOAT et al., I998). A primeira correlação a deduzir entre a globalização, o mercado e a sociedade é, indelevelmente, circunscrita às causas e aos efeitos geográficos e temporais resultantes da acção das TIC. A latitude e a importância desta realidade é incontestável. São exemplos emblemáticos das contingências da globalização, quando discernimos na intensidade e extensão desse fenómeno de aculturação e de aprendizagem social à escala local, regional, nacional e mundial, pela via do audiovisual através dos mass media e da televisão em particular. Enquanto elementos crescentemente cruciais na aculturação e na aprendizagem social do factor de produção trabalho a um outro nível do espaço-tempo do consumo, saliente-se a força estruturante da "internet", do ciberespaço, da web, das "nanotecnologias", das biotecnologias, da inteligência artificial, robótica, biociência, telemática, informática etc. (GIBSON, 2004; LEARY, I990; CASTELLS, 2002, 2003a, 2003b, 2004). Com base nesta evolução estruturante, torna-se, hoje, quase impossível sobreviver de forma sustentável, como trabalhador assalariado, no quadro da racionalidade instrumental do capitalismo, caso as suas qualificações e competências não lhe permitirem atempada e adequadamente descodificar e codificar as linguagens das TIC. Na verdade, se pensarmos nas características da informação, do conhecimento e da energia que é possível socializar como inputs e outputs, quer em termos quantitativos ou qualitativos; se pensarmos, ainda, nos meios e nas formas que existem 
para os emitir, transmitir, apercebemo-nos facilmente das repercussões das TIC e da globalização traduzidas numa capacidade/possibilidade inaudita de produção, distribuição, troca e consumo de bens e serviços de carácter analítico-simbólico. Partindo deste pressuposto, a globalização é a configuração espácio-temporal da coincidência do espaço-tempo virtual com o espaço-tempo real, da força estruturante do espaço-tempo do presente assente na instantaneidade e simultaneidade de cada realidade humana biológica e social concreta inscrita em fluxos e redes de informação, conhecimento e energia de carácter abstracto e complexo. Este dilema do factor de produção trabalho não é circunscrito à esfera da produção, nem tampouco às qualificações e competências dos diferentes perfis profissionais. A instantaneidade do espaço-tempo obriga-o a adquirir competências e qualificações que lhe permitem intervir, simultaneamente, na esfera da distribuição, da troca e do consumo de bens e serviços analítico-simbólicos. Nestes domínios se não transformar num actor eficiente e eficaz, nunca poderá emergir à condiçãofunção de factor de produção trabalho no quadro da racionalidade instrumental do capitalismo.

Esta padronização espácio-temporal de bens e serviços é produto da acção das transnacionais que operam no mercado mundial e é vital para os ditames do desenvolvimento da economia formal e informal (SENNETT, 200I). Estas, por sua vez, tornaram-se mais interdependentes e complementares. A instantaneidade e a simultaneidade cognitiva, emocional e física de cada indivíduo concreto como factor de produção trabalho é crucial para os integrar nos fluxos e nas redes de informação, energia e conhecimentos resultantes da acção desterritorializada das transnacionais. Quem não possui informação, conhecimento e energia reportada a esses fluxos e redes é excluído da produção, distribuição, troca e consumo dos bens e serviços analítico-simbólicos. Esta tendência da globalização é estruturada pela crescente integração da ciência e técnica corporizada na inovação e mudanças das TIC. Como factor de adaptação e de reaç̧ão a essas inovações e mudanças, cada indivíduo concreto, independentemente do país, da cultura, do território e do perfil profissional que integre, é, antes demais, um actor-consumidor (BAUMAN, 200I). No fundo, o tempo presente de cada indivíduo concreto face às contingências da modernidade analítico-simbólica da globalização é atravessado pelo consumo de informação, conhecimento e energia circunscrita à atomização e alienação da sua vida quotidiana, provocada pela abstracção e complexidade de estímulos provenientes da sociedade globalizada. Através da procura efectiva, esta, por sua vez, induz à oferta efectiva de produção de bens e serviços analítico-simbólicos e, logicamente, da distribuição e troca decorrente da acção das transnacionais no mercado mundial.

Este modelo personificado pelas actividades das empresas transnacionais se bem que não seja o mais representativo em países cuja actividade económica 
incide no sectores agrícola e industrial - cereais, indústria agro-alimentar, automóveis, construção civil, química, metalurgia e têxteis - neste caso, as novas tecnologias reportam-se à informática, à micro-electrónica, às máquinas-ferramentas de comando numérico, à biotecnologia e robótica. Em termos espáciotemporais, a produção, distribuição, troca e consumo destes bens e serviços são estruturados através de uma rede complexa e abstracta, tendo por base um imenso trabalho social automatizado integrado nessas tecnologias. Para descodificar e codificar essas linguagens também são exigidas novas competências do factor produção trabalho e, logicamente, de todos os perfis profissionais que recorrem à informação, à energia e ao conhecimento.

Não obstante o recurso à utilização massiva de matérias-primas e energia de características materiais decorrentes do processo de industrialização e de urbanização de países capitalistas menos desenvolvidos, essa realidade não contraria, de modo algum, a evolução da necessidade imperativa de qualificações e competências do factor de produção trabalho de serem integrantes e restritas a causalidades e efeitos da natureza cognitiva e emocional, em detrimento de competências e qualificações baseados em gestos, movimentos e pausas de carácter energético do factor de produção trabalho. Esta tendência perde muita da sua importância, na medida em que parte substancial da matéria prima é redutível à informação, ao conhecimento e à energia de características imateriais dos custos de produção que são transformados no processo de trabalho. Pela sua natureza analítico-simbólica, a intervenção das TIC são cruciais nesse processo. Por um lado, potenciam e viabilizam coincidência do espaço-tempo virtual com o espaço-tempo real das actividades produtivas e das actividades de consumo. Por outro, padronizam, atempada e adequadamente, as modalidades de produção, troca, distribuição e consumo à escala universal, recorrendo para o efeito a uma estrutura de custos imateriais baseados em inputs de informação e de conhecimento adstritos às funções e tarefas do factor de produção trabalho (GOLDFINGER, I998).

Em segundo lugar, a crescente integração da ciência e da técnica no quadro da racionalidade instrumental do capitalismo tem-se traduzido numa crescente racionalização da organização do trabalho. Como resultado, assistimos ao desenvolvimento da desterritorialização da inovação e das mudanças com base nas novas tecnologias e, por conseguinte, do desenvolvimento da energia, da informação e do conhecimento inscritos na acção individual e colectiva do factor de produção trabalho na sociedade global. Com base nos fluxos e nas redes de informação, conhecimento e energia veiculados pelas TIC das transnacionais ao nível local, regional, nacional, continental e mundial, os espaços-tempos decorrentes da acção individual e colectiva do factor de produção nos domínios da divisão do trabalho, dos níveis hierárquicos da autoridade formal, do processo de tomada de decisão e do processo de liderança são cada vez mais interdepen- 
dentes e complementares, como inclusive constrangem a que a transformação espácio-temporal dos inputs em outputs seja, exclusivamente, realizada com base na coincidência do espaço-tempo virtual com o espaço-tempo real. No sentido extenso e profundo do termo, cada segundo, cada minuto, cada hora ou dia de produção, distribuição, troca e consumo de mercadorias analítico-simbólicos são restritos e esgotam-se definitivamente no espaço-tempo da instantaneidade e da simultaneidade em que foram produzidos, distribuídos, trocados e consumidos. Neste contexto, só é possível ser actor de produção, distribuição, de troca e de consumo num espaço-tempo irrepetível da vida quotidiana de qualquer indivíduo, em qualquer processo de trabalho, em qualquer espaço-tempo de consumo (aldeia, vila, cidade, hipermercado, aeroporto, café, banco) ou em qualquer espaço-tempo familiar. Só existe o espaço-tempo presente confinado à multiplicidade dos fluxos e das redes de informação, conhecimento e energia que corporizam as acções concretas e abstractas que integram a actual racionalização da organização do trabalho à escala mundial (FERREIRA, 2005; EME; LAVILLE, I994). Pode-se acontecer o oposto, mas então o factor de produção está num espaço-tempo de omissão, de incapacidade manifesta de actuar como actor proficiente no quadro da racionalidade instrumental do capitalismo.

$\mathrm{Na}$ actualidade, é fundamental referir que a inovação e mudança operadas no âmbito das TIC não têm limites nos parâmetros normativos da racionalidade instrumental do capitalismo. A plasticidade social das causas e dos efeitos já provocados por essa racionalidade embora se manifestem, com maior ênfase, nas actividades económicas e financeiras que resultam da expansão do mercado mundial, por outro lado, a tendência estruturante actual incide, exponencialmente, nas actividades sociais, políticas, científicas e culturais. Nesta assunção, somos constrangidos a compreender as TIC, e as suas correlações com o conceito tempo, enquanto um fenómeno essencialmente civilizacional (ELIAS, I998; MUMFORD, I974). Como hipóteses de estímulos e respostas, os actores individuais e colectivos, não sendo semelhantes na generalidade das famílias, organizações, comunidades, regiões, dos países e continentes que integram o planeta Terra, são, no entanto, sujeitos e objectos do mesmo modelo padrão de codificação e descodificação de linguagens. Esse facto, por si só, leva-os a integrar um processo de aprendizagem social e de aculturação circunscrito a signos e significados identificados com o mesmo tipo de valores, de moral, de política e de relações sociais.

Sendo actores concretos de adaptação e de reacção a uma produção de estímulos complexos e abstractos, as respostas de qualquer actor tem que integrar sempre a uma aprendizagem social e aculturação das TIC. Na medida em que os estímulos provenientes das TIC tendem para uma probabilidade infinita, a capacidade/possibilidade de resposta de cada indivíduo ou grupo, em termos cogni- 
tivos, emocionais e físicos, tende a diminuir drasticamente no espaço-tempo da sua vida quotidiana. O tempo de resposta deve corresponder imperativamente ao tempo do presente de cada estímulo, ou então o tempo circunscrito à vida de cada indivíduo ou grupo torna-se um mero simulacro existencial. Compreendem-se, assim, os índices de analfabetismo, de desemprego, de exclusão social, de miséria e pobreza a nível da população mundial. Nestas circunstâncias, qualquer actor individual ou colectivo não é parte integrante dos fluxos ou redes de informação, conhecimento e energia que configuram a actual evolução das TIC no quadro da racionalidade instrumental do capitalismo. A grande maioria da população mundial está fora deste processo, daí que engrosse o mundo da exclusão social, da pobreza, do desvio e do crime.

Para responder às vicissitudes e contingências das TIC, o tempo, como categoria sociológica de uma série de representações sociais, está subordinado a uma mera réplica mecânica de modelos normativos de acção individual ou colectiva. No entanto, esta concepção tem pouca validade heurística. Qualquer indivíduo ou grupo, em qualquer organização ou instituição, como probabilidades de resposta aos modelos institucionalizados de cultura normativa (PARSONS, I982), sujeita-se, em princípio, a adaptações funcionais e normativas. No caso específico das contingências das TIC, essas funções adaptativas não são realizadas de forma atempada e adequada. Sendo meras réplicas do passado de modelos institucionalizados de cultura normativa, hoje, enquanto sistemas processadores de informação, conhecimento e energia, qualquer indivíduo ou grupo têm extrema dificuldade em sentir, agir e pensar de forma espontânea e informal, na medida em que os constrangimentos estruturais e institucionais dos valores, das normas e das regras das sociedades e organizações em que se inserem o impedem ou condicionam. Face a esta realidade, a emergência criativa adstrita às funções cognitivas, emocionais energéticas de cada indivíduo ou grupo revela-se impossível. Sendo sujeitos de causalidades e efeitos normativos e institucionalizados, têm extrema dificuldade em se tornarem actores produtores de sentido em conformidade com a sustentabilidade e reprodutibilidade do modelo sócio-político e cultural desenvolvido pelas TIC.

Como consequência da manifesta incapacidade da produção de sentido por partes dos actores individuais e colectivos, as disfunções e perversões económicas, políticas, sociais, organizacionais, culturais e civilizacionais têm-se desenvolvido de forma abrupta e exponencial. Os exemplos das guerras regionais, da destruição do planeta Terra, do desemprego, da fome, da miséria e do crime são as expressões mais representativas de uma guerra civil interindividual ao nível mundial. Neste âmbito, o tempo do presente, da instantaneidade e da simultaneidade, é um tempo histórico do desvio e da transgressão em relação à estabilidade normativa da racionalidade instrumental do capitalismo (LALLEMENT, 
I994). As contingências da globalização e das TIC estão mais uma vez presentes na estruturação de acções individuais e colectivas cuja síntese culmina na formação de relações sociais informais e espontâneas, traduzindo-se numa gigantesca economia subterrânea. A complexidade e a abstracção deste tipo de economia é atravessada pela precariedade e efemeridade da vinculação contratual, da inexistência de direitos sociais de carácter formal, de salários de miséria (SUPIOT, I999; PINARD, 2000; DUPAS, I999). Parece paradoxal mas não é. A subcontratação generalizada deste tipo de actividades económicas por parte das grandes transnacionais permite que estas reduzam a sua estrutura de custos de produção e que, por outro lado, potenciem enormemente as suas capacidades de produção, distribuição, troca e consumo de bens e serviços com objectivos exclusivos de controlar as funções desviantes e disfuncionais da economia subterrânea. Neste tipo de economia emergem as mesmas vicissitudes da coincidência do espaço-tempo virtual com o espaço-tempo real das actividades económicas que lhe são subjacentes. A instantaneidade e a simultaneidade de cada cognição, emoção e energia do factor de produção trabalho também se esgota no tempo presente do desvio, da informalidade e da espontaneidade que integra a produção, a distribuição, a troca e o consumo do crime, da violência, da droga, da miséria, do desemprego ou da exclusão social.

\section{AS TECNOLOGIAS DE INFORMAÇÃO E COMUNICAÇÃO (TIC) E O ESPAÇC- TEMPO DA ORGANIZAÇÃO DO TRABALHO}

Quando discernirmos sobre a crescente racionalização da organização do trabalho, estamos a raciocinar nas características e no grau de institucionalização e de formalização inscritas nas funções e tarefas do factor de produção trabalho no contexto da racionalidade instrumental do capitalismo. No cômputo geral da evolução sócio-histórica desse processo subsistem quatro elementos estruturais e institucionais que não podemos prescindir de analisar: refiro-me à divisão do trabalho, à estrutura hierárquica da autoridade formal, ao processo de tomada de decisão e ao processo de liderança.

São elementos cruciais de racionalização da energia, das cognições e emoções que integram a acção dos indivíduos e grupos que trabalham em qualquer organização ou instituição. São factores de prevenção e controle e de prevenção que padronizam, cuja função é evitar ou condicionar, de uma forma atempada e adequada, qualquer tipo de disfunção cognitiva, emocional e energética que possa, hipoteticamente, perverter ou limitar os objectivos da máxima produtivi- 
dade e rendibilidade do factor de produção trabalho. No entanto, a racionalização do espaço-tempo inscrito na acção do factor de produção trabalho, enquanto medida quantitativa e qualitativa dos gestos, das pausas e dos movimentos no contexto da organização científica do trabalho, foi, em grande parte, concebida por Frederick Taylor (1965). Como categoria conceptual empírica atingiu enorme plasticidade social na primeira e na segunda revolução industrial, na medida em que as empresas tiveram a capacidade de racionalizar e integrar esses factores na psique, na mente e, sobretudo, nas potencialidades energéticas do factor de produção trabalho no processo de trabalho através da sua institucionalização e formalização nas tarefas e funções que integram a divisão do trabalho, a autoridade hierárquica formal, o processo de tomada de decisão e o processo de liderança. Não obstante a excessiva formalização e institucionalização confinadas ao espaço-tempo da concepção, do controlo e da execução de tarefas e funções, o espaço-tempo dos gestos, dos movimentos e das pausas do factor de produção trabalho foi reduzido substancialmente. Por sua vez, a acção individual e colectiva do factor de produção trabalho dos diferentes perfis profissionais, ao ser objecto de uma padronização generalizada com base no dispêndio de energia física, simultaneamente traduziu-se na redução do espaço-tempo confinado às tarefas e funções de cariz cognitivo e emocional.

A separação espácio-temporal da concepção, do controle e da execução de tarefas culminou, muitas vezes, em mudanças estruturais e institucionais baseadas na memória dos modelos normativos da organização científica do trabalho e servia e serve, ainda, como réplicas mecânicas de mudança de um espaçotempo confinado às lógicas do curto, do médio e longo prazos. Nestas condições, o passado determina o presente, e o futuro não passa de uma miragem baseada numa multidão de equívocos. As características estáticas da memória ao nível da divisão do trabalho e da autoridade da hierarquia formal remetem para a gestão de topo e para os quadros técnicos intermédios as funções de concepção e de controle, deixando para os trabalhadores assalariados da base da pirâmide organizacional a execução de tarefas.

Por sua vez, o processo de tomada de decisão e o processo de liderança, não obstante também personificarem singularidades específicas de racionalização organização do trabalho de natureza estática, são elementos estruturais e institucionais de natureza mais dinâmica. Neste contexto, os indivíduos e grupos que integram qualquer organização do trabalho são sujeitos a tipologias de interacção social no processo de trabalho. O carácter dinâmico dessas interacções sociais constrangem a acção individual e colectiva dos diferentes actores e perfis profissionais a assumirem papéis pautados pela informalidade e espontaneidade.

Para os devidos efeitos, emergem facilmente para um conjunto de relações diversificadas: intrapessoais, interpessoais, intragrupais, intergrupais, intra- 
organizacionais e interorganizacionais. Assim sendo, qualquer organização ou empresa é um sistema aberto em interdependência sistemática e profunda com o ambiente externo próximo ou o ambiente externo longínquo, quer na compra dos seus inputs quer na venda dos seus outputs. Esta troca sempre integrou e integra informação, energia e conhecimento. O processo de tomada de decisão é uma dinâmica específica no âmbito da organização do trabalho que envolve compreensão e participação dos vários actores e perfis profissionais de uma dada organização. É uma participação e compreensão da socialização da informação, do conhecimento e da energia reportada à transformação, atempada e adequada, de inputs em outputs e, logicamente, envolve ainda a distribuição, a troca e o consumo desses bens e serviços na sociedade global. Desde o topo até à base da pirâmide organizacional subsistem prescrições padronizadas no processo de tomada de decisão que decorrem da divisão do trabalho e da autoridade hierárquica formal. Todavia, se inscrevermos nesse processo a socialização da informação, da energia e do conhecimento inerente à compreensão e à participação dos diferentes actores e perfis profissionais, a emergência do espaço-tempo da informalidade e da espontaneidade revela-se crucial para a dinâmica e eficiência do processo de tomada de decisão nas organizações.

No contexto da organização do trabalho, o processo de liderança é um elemento estrutural e institucional de capital importância. As suas correlações com a divisão do trabalho e a autoridade hierárquica formal, embora a sua plasticidade social seja pertinente em termos do processo de liderança formal, no espaçotempo das contingências das TIC e da globalização os seus efeitos estruturantes são cada vez mais irrelevantes. A plausibilidade desta análise decorre do facto dos papéis individuais circunscreverem variadíssimas vezes ao espaço-tempo das relações interpessoais, intrapessoais e intragrupais, ao mesmo tempo que se revelam menos activos no espaço-tempo circunscrito às relações intergrupais, intra-organizacionais e interorganizacionais. De facto, o processo de liderança para além de ser uma réplica da legitimação e institucionalização dos líderes com características formais, isso não obsta que o conhecimento, a informação e a energia inscritos na aprendizagem, personalidade e capacidade perceptiva dos diferentes actores sejam os factores primaciais de influência social e, consequentemente, de causalidades e efeitos de liderança. Neste caso, é previsível a emergência de um processo de liderança informal circunscrito ao nível educacional e cultural dos diferentes indivíduos que trabalham em qualquer organização ou instituição. No caso específico da mediação das TIC como meio de comunicação crucial, as relações entre líderes e liderados podem ser positivas desde que os diferentes órgãos sensoriais dos diferentes actores envolvidos nesse processo possam evoluir de uma forma espontânea, informal e autónoma. Deste contexto emergem exponencialmente os papéis do líder informal. As contingências da coincidência do espa- 
ço-tempo virtual com o espaço-tempo real atravessam as relações interpessoais e intragrupais de características espontâneas e informais e, por outro lado, fazem emergir as capacidades cognitivas, emocionais e energéticas de qualquer líder em termos intrapessoais. No espaço-tempo deste tipo liderança informal que decorrem, em grande parte, das contingências da globalização e das TIC, não é sustentável manter a actual institucionalização e formalização da divisão do trabalho e da autoridade hierárquica formal. Estas revelam-se contraproducentes e perversas, na medida em que condicionam ou inviabilizam qualquer tipo de influência de líderes informais sobre um dado grupo ou organização.

\section{O EXEMPLO DA ORGANIZAÇÃO DO TRABALHO DO MODELO UNIVERSITÁRIO PORTUGUẾS}

Para evitar generalizações abusivas, na minha opinião, é possível equacionar a actualidade destes quatro elementos fulcrais da organização e do processo de trabalho, recorrendo, para esse efeito, a uma análise sucinta do modelo de organização do trabalho do universo universitário português. Esta análise não é restrita a qualquer universidade pública ou privada do espaço geográfico português. Para além da minha experiência de várias décadas decorrente do perfil profissional dos professores universitários portugueses, a observação participante, reflexões e análises nos planos científico, pedagógico e organizacional (FERREIRA, I998a, I998b) permitem-me extrair algumas ilações compreensivas e explicativas que importa referenciar.

Devo sublinhar que a pertinência da análise do modelo universitário português decorre de outros factores não menos importantes. Em primeiro lugar, estamos a debruçar-nos sobre um sector de actividade centrado na produção, na distribuição, na troca e no consumo de bens e serviços de características analítico-simbólicas: formação, educação, investigação aplicada e investigação fundamental. Em segundo lugar, a crescente integração da ciência e da técnica está na origem e desenvolvimento exponencial das TIC e, por outro lado, da própria globalização. Em terceiro lugar, as necessidades prementes de inovação e mudanças na investigação, educação e formação de "recursos humanos" reportados à multiplicidade de papéis e perfis profissionais das actividades económicas, sociais, políticas e culturais à escala mundial, constrangem, problematizam e desafiam as universidades a transformações inauditas nos planos organizacional, pedagógico e científico.

Neste período histórico, por outro lado, o modelo universitário português, como sistema aberto, é objecto de uma série de adaptações e reacções prove- 
nientes das inovações e mudanças provocadas pelas TIC e pela globalização. Estas, através do desenvolvimento intensivo e extensivo de fluxos de informação, de energia e conhecimento na forma de inputs (alunos, funcionários e professores) e a sua consequente transformação em outputs (formação, educação, investigação) constrangeram as universidades portuguesas a evoluir no sentido de uma maior integração no mercado mundial de produção, distribuição, troca e consumo de bens e serviços científicos. Como qualquer outro bem ou serviço, no quadro da racionalidade instrumental do capitalismo, a ciência é potenciadora ou não da maximização do lucro. Seguindo este raciocínio, enquanto meio de eficácia e de eficiência, todo e qualquer factor de produção trabalho ou perfil profissional que integra a organização do trabalho do modelo universitário português é compelido a realizar índices de produtividade semelhantes àqueles que são praticados em nível mundial.

Assim sendo, não é mais possível analisar os problemas e os desafios que se apresentam à organização do trabalho do modelo universitário português através de paradigmas ou autores que não são mais de que meras réplicas científicas da segunda revolução industrial. A plausibilidade desta análise, como já enunciei, reside no espaço-tempo reportado à instantaneidade e à simultaneidade de produção, distribuição, troca e consumo de bens de natureza científica. A informação, a energia e o conhecimento enquanto inputs ou "matérias-primas" básicas das universidades portuguesas não são exteriores à sua transformação em outputs produzidos (educação, formação e investigação) pelos estudantes, funcionários e professores. Não só existe uma interdependência e complementaridade sistemáticas entre a teoria e a prática, entre o espaço-tempo interno e o espaço-tempo externo, como também entre as realidades biológica e física e a realidade social. Por sua vez, qualquer cognição, emoção ou dispêndio energético de cada actor ou perfil profissional integrante da organização do trabalho do modelo universitário português, em qualquer contexto-situação de produção, distribuição, troca e consumo de bens científicos emergem, exclusivamente, no espaço-tempo presente de cada segundo, minuto, hora e dia em que interagem na sala de aula, no laboratório, na biblioteca ou noutro espaço-tempo da organização do trabalho. São temporalidades e territorialidades de produção, distribuição, troca e consumo de educação, de formação e de investigação de um só presente e irrepetíveis.

Dando início à análise concreta do universo universitário português, parece que é na estrutura hierárquica da autoridade formal que subsistem os problemas e desafios maiores da organização do trabalho. Enquanto sistema e subsistema da sociedade global, o Estado e o sistema universitário português são simultaneamente sistemas abertos e estruturas jurídicas atravessadas por um conjunto de leis, normas e regulamentos estreitamente correlacionados com o processo de tomada decisão do investimento e da propriedade do capital com características abstractas 
e complexas. Desse modo, no topo da estrutura hierárquica da autoridade formal do sistema universitário português subsiste o governo: ou seja, actualmente o Ministério da Ciência, Tecnologia e Ensino Superior e, antes, variadíssimas vezes, denominado Ministério da Educação. Não obstante a entrada de Portugal na Comunidade Económica Europeia (CEE) em I986, seja pela adopção da Lei da Autonomia Universitária, do Estatuto da Carreira Docente Universitária (ECDU), da Lei de Bases do Sistema Educativo ou, mais recentemente, da Lei de Bases do Financiamento do Ensino Superior, em última instância, qualquer decisão ou regulamentação de carácter normativo com incidência substantiva na mudança ou continuidade da estrutura da autoridade hierárquica formal resultam da acção do governo ou do ministério articulado com o ensino superior.

No amplo sentido do termo, a rigidez e as perversões subsistentes na organização do trabalho do modelo universitário português são o resultado da manifesta incapacidade decisória dos diferentes governos e ministérios. Estes limitam-se de uma forma não adequada e não atempada a reproduzir mecanicamente modelos externos que não conhecem e, muitas vezes, para reproduzir as idiossincrasias do poder e das funções da autoridade burocrática estatal. A este poder e autoridade do topo hierárquico do sistema universitário, em termos de subalternidade e níveis hierárquicos intermédios, segue-se a dos reitores e dos senados das diferentes universidades, culminando nas unidades orgânicas (faculdades, escolas, institutos, departamentos) da base da pirâmide hierárquica.

Como elemento estruturante da organização do trabalho, as funções e o poder adstrito às capacidades/possibilidades dos níveis hierárquicos superiores são relevantes. Em primeiro lugar, porque estão ligados às probabilidades ou não de reflexão e decisão sobre as mudanças que estão sendo operadas pela globalização e pelas TIC nos domínios da ciência, educação, formação, investigação e, como dedução lógica, da sua incrustação na organização do trabalho no que respeita à necessidade ou não de mais ou menos níveis de autoridade hierárquica formal. Como já referimos, qualquer decisão indirecta ou directamente está reportada à transformação de inputs de informação, energia e conhecimento em outputs de educação, formação e investigação, de forma atempada e adequada. Não é isto que ocorre no sistema universitário português. Através do excessivo número de níveis de autoridade hierárquica formal, a emissão e a recepção de informação, conhecimento e energia é condicionada, omitida e pervertida pela incapacidade cognitiva, emocional e energética da burocracia política e profissional. A explicação plausível desta tendência reside no facto dessas estruturas burocráticas impedirem a emergência de relações interpessoais informais e espontâneas entre chefes e subordinados.

A continuidade e a expressão substantiva da autoridade hierárquica formal na organização do trabalho do modelo universitário português é visível, funda- 
mentalmente, nas relações entre professores catedráticos, professores associados, professores auxiliares, assistentes e assistentes auxiliares. É preciso não esquecer que o espaço-tempo do exercício efectivo dessa autoridade, embora seja mais expressivo em nível da reitoria e do senado e, em termos hierárquicos subsequentes, nos conselhos directivos, conselhos científicos e pedagógicos das unidades orgânicas das universidades, tem também um espaço-tempo privilegiado: salas de aula, centros e laboratórios de pesquisa, bibliotecas e espaços confinados à administração. A autoridade hierárquica formal neste espaço-tempo da organização do trabalho reside na relação de poder dos professores com os alunos e com os funcionários. Entre estes existem uma relação baseada na autoridade hierárquica formal proveniente da administração pública, mas, em última instância, correlacionada especificamente com o sistema universitário português.

No caso específico dos professores, a manutenção dos níveis hierárquicos de autoridade formal na organização do trabalho na base da pirâmide do sistema universitário português é contraproducente, perversa e disfuncional em relação aos actuais ditames da racionalidade instrumental do capitalismo. Se aos professores catedráticos, pela suas funções e qualificações, lhes são exigidas competências e qualificações superiores às dos professores associados e a estes competências superiores às dos professores auxiliares e a estes competências superiores às dos assistentes, com as contingências de competição e de concorrência provocadas pelas TIC e da globalização, tudo isso se revela, cada vez mais, inconsequente. A memória e o passado, assim como a antiguidade, no caso dos professores catedráticos, revelam-se pouco ou nada proficientes em qualquer sala de aula. Na actualidade, tudo isso não é suficiente, tendo presentes os constrangimentos cognitivos, emocionais e energéticos intrapessoais e interpessoais que a cada minuto, segundo ou hora são obrigados a viver na sala de aula como actores comunicantes de aprendizagem e não de transmissão mecânica de conhecimentos, de energia e informação. Seguindo este raciocínio, o mesmo se pode referir a toda e qualquer pesquisa realizada em forma de artigo ou livro que sirva exclusivamente como réplica "cosmética" e mecânica de transmissão de conhecimentos de modelos ou paradigmas científicos.

Se na sala de aula ou em qualquer centro ou laboratório de pesquisa, o espaço-tempo do nosso presente é a aprendizagem e não a transmissão de conhecimentos, porque só assim somos actores de comunicação, de auto-educação, de auto-formação e de pesquisa, então cada actor-professor, seja ele catedrático, associado, auxiliar ou assistente, só pode emergir com as suas capacidades cognitivas, emocionais e energéticas se evoluir num espaço-tempo de liberdade, criatividade e responsabilidade circunscritas à espontaneidade e à informalidade relacional. Para este efeito, não há necessidade alguma de níveis hierárquicos de autoridade formal, na medida em que, não obstante, a sua persistência não opti- 
miza o grande desiderato da racionalidade instrumental do capitalismo: maximização do lucro através da máxima produtividade do factor de produção trabalho.

Ao consideramos os efeitos perversos da organização do trabalho do modelo universitário português, a relação baseada na autoridade hierárquica formal dos professores sobre os estudantes e os funcionários ainda é mais negativa e contraproducente. O poder absoluto da autoridade hierárquica do professor inscrito nas funções de transmissão de conhecimentos na sala de aula transforma estes em progenitores e emissores exclusivos de informação, conhecimento e energia. Os estudantes, pelo seu lado, transformam-se em meros simulacros da recepção de informação, energia e conhecimento, sendo constrangidos a comportar-se como uma entidade cognitiva, emocional e energética passiva e omissa na sala de aula.

A dimensão desta relação baseada na autoridade hierárquica dos professores sobre os funcionários, se bem que diferente dos estudantes na organização do trabalho do modelo universitário português, tem a sua tradução empírica nas interdependências e complementaridades nas funções e tarefas de carácter científico, pedagógico e organizacional. Em qualquer circunstância, a comunicação entre professores e funcionários é crucial, sendo de uma enorme importância para eficácia das suas funções e tarefas. Os funcionários tendo um papel de subalternização ou de dependência generalizada em relação às suas funções e tarefas específicas, na sala de aula ou em qualquer outro espaço-tempo da organização do trabalho, limitam-se a reproduzir mecanicamente as decisões decorrentes da autoridade hierárquica formal dos professores, nomeadamente dos catedráticos.

O segundo elemento estrutural importante da organização do trabalho do modelo universitário português deve referir-se à divisão do trabalho. Este elemento institucionaliza e legitima o factor de produção trabalho na organização do trabalho do modelo universitário português com base nas tarefas e funções adstritas aos perfis profissionais dos professores, dos funcionários e dos estudantes. Através da divisão do trabalho, as qualificações e competências específicas de cada perfil profissional têm um carácter prescritivo e padronizado no espaço-tempo de salas de aula, bibliotecas, laboratórios, centros de investigação e espaços administrativos. As interdependências e complementaridades entre os três perfis profissionais pela sua especificidade não são redutíveis ou decalcadas exclusivamente do exercício do poder inerente à autoridade hierárquica formal. A socialização da informação, da energia e do conhecimento decorrente das qualificações e competências dos professores, estudantes e funcionários é realizada num espaço-tempo de horizontalidades cognitivas, emocionais e energéticas. A emergência da espontaneidade e da informalidade das relações intrapessoais, interpessoais, intragrupais, intergrupais e intra-organizacionais confinadas à 
coopresença física e ao interconhecimento condiciona, subverte ou inviabiliza o carácter prescritivo do poder e da autoridade hierárquica de natureza vertical.

Depreende-se, assim, do enorme impacto das contingências das TIC e da globalização correlacionadas com as competências e qualificações dos três perfis profissionais da organização do trabalho do modelo universitário português. De facto, a instantaneidade e a simultaneidade de produção, distribuição, troca e consumo de bens e serviços de características analítico-simbólicas reduz-se ao espaço-tempo de qualquer sala de aula, laboratório, biblioteca ou centro de investigação. Cada segundo, minuto, hora ou dia ou é propício a uma aprendizagem sistemática e profunda por parte dos diferentes actores que intervêm no processo do trabalho do modelo universitário português, ou então estamos no tempo histórico da repetição e da transmissão de conhecimentos movida pela força da inércia de modelos ou paradigmas científicos de um passado de não probabilidades de emergir no presente. $\mathrm{O}$ atraso e o subdesenvolvimento das qualificações e competências dos perfis profissionais inscritos na actual divisão do trabalho da organização do trabalho do modelo universitário português é consequência e tem as suas raízes profundas na última hipótese que acabo de referir.

O dilema do actual desajustamento estrutural e funcional da divisão do trabalho do modelo universitário português não é exclusivamente científico e organizacional, a sua visibilidade maior é de características pedagógicas. As relações entre professores e alunos e entre estes e os funcionários não permitem ou então inviabilizam qualquer tipo de aprendizagem na sala de aula ou fora dela. A separação espácio-temporal das aulas teóricas das aulas práticas resulta numa imensa frustração de aprendizagem quer para professores quer para alunos. A manifesta impossibilidade de professores, alunos e funcionários de "aprenderem-fazendo" é bastante representativa nas aulas teóricas em turmas com mais de ioo alunos. Nas aulas práticas procura-se reaprender o que não se aprendeu nas aulas teóricas. Os alunos são transformados em meros "caixotes de lixo", pois limitam-se a memorizar conceitos e a tentar relacionar conceitos que facilmente esquecem e que, depois, ao pretenderem novamente memorizar para os exames e os testes, esquecem-nos definitivamente. Verifica-se, assim, que cada segundo, minuto, hora ou dia não é simultaneamente um acto de aprendizagem e de produção, distribuição, troca ou consumo de bens e serviços científicos integrados na vida quotidiana da organização do trabalho do modelo universitário português. Neste domínio, em termos de causalidades e efeitos, o panorama pedagógico é perpassado pela frustração e pela omissão no que se reporta às funções comunicacionais e afectivas decorrentes das tarefas e funções dos professores, alunos e funcionários no contexto da actual divisão do trabalho do modelo universitário português.

Seguindo o mesmo raciocínio, importa agora debruçar-nos sobre o processo de tomada de decisão no contexto da organização do trabalho do modelo uni- 
versitário português. O carácter dinâmico do processo de trabalho está intimamente correlacionado com o processo de tomada de decisão no espaço-tempo circunscrito à organização do trabalho. Partindo desta premissa básica, cada actor individual e colectivo está sempre articulado com a socialização da informação, do conhecimento e da energia integrada na compreensão e participação do processo de tomada de decisão. Esta compreensão e participação decorre da execução de tarefas e funções concernentes a qualquer processo de tomada de decisão. Nos caso específico da organização do trabalho do modelo universitário português, qualquer actor individual ou colectivo é, antes de mais, um sistema processador de informações, de conhecimento e energia que tem capacidades ou não de, atempada e adequadamente, categorizar a informação, a energia e o conhecimento correlacionados com os papéis, as qualificações e competências determinados prescritivamente pelo lugar que ocupam na divisão do trabalho e na autoridade hierárquica formal.

Como conseqüência, em quaisquer circunstâncias, os professores nas relações com os alunos e funcionários são determinantes no processo de tomada de decisão, na medida em que as tarefas e funções os remetem exclusivamente para o papel de emissores de informação, conhecimento e energia. Em contrapartida, os estudantes limitam-se ao exercício de funções e tarefas de subalternização cognitiva, emocional e energética, servindo como meros receptáculos de informação, energia e conhecimento transmitidos pelos professores. Estes, na maioria dos casos, reproduzem mecanicamente os programas das disciplinas científicas que integram e limitam-se a influenciar e a determinar o processo de tomada de decisão nesse sentido. No que concerne aos aspectos organizacionais, o peso da estrutura hierárquica formal do Estado português dá maior relevo às funções decalcadas da administração pública. Não admira, assim, que os funcionários que integram o topo hierárquico da organização do trabalho do modelo universitário português sejam, em parte, determinantes no processo de tomada de decisão e emirjam fulcralmente como emissores e não como meros receptáculos de energia, informação e conhecimento.

Partindo da análise que já elaborei em relação às contingências das TIC e da globalização, não restam dúvidas de que no processo de tomada de decisão, qualquer professor, estudante ou funcionário, enquanto sistemas processadores de informações (NEVES, 200I), para serem sujeitos de eficácia e de eficiência no contexto da racionalidade instrumental do capitalismo, terão que, atempada e adequadamente, categorizar a informação, o conhecimento e a energia que são nucleares para estruturar o "saber-fazer" que integra as competências e qualificações dos perfis profissionais a que estão ligados. Para este efeito, para subsistir no espaçotempo da instantaneidade e simultaneidade que integra o processo de tomada de decisão, é inelutável que cada actor emirja como emissor e receptor de informa- 
ção, conhecimento e energia. Só, nestas condições, é possível integrar o processo de tomada de decisão de forma efectiva e eficiente, na medida em que ele é um processo de socialização atravessado pela compreensão e participação de todos os actores nele envolvidos.

Neste caso, mais uma vez, o exemplo do processo de tomada de decisão da organização do trabalho do modelo universitário português revela-se desajustado e perverso. A quase totalidade das decisões revelam-se ineficientes em termos da análise custos-benefícios e revelam-se, sistematicamente, tardias em relação às temporalidades da concorrência e da competição, quer em nível do mercado nacional, quer em nível do mercado europeu ou do mercado mundial. O mais dramático é quando nos circunscrevemos ao espaço-tempo da organização do trabalho na sala de aula. Neste espaço-tempo só os professores são sujeitos activos no processo de tomada de decisão. Os estudantes e os funcionários são transformados em meras figuras de memorização e de subalternização da compreensão e da participação que é crucial para que qualquer processo de tomada de decisão se traduza objectivamente em produção, distribuição, troca e consumo de bens e serviços de natureza científica.

Por último, no tempo histórico das contingências das TIC e da globalização, a plasticidade social do processo de liderança na organização do trabalho do modelo universitário português revela-se, tendencialmente, cada vez mais pertinente. Este elemento estrutural da organização do trabalho é importante analisar por duas razões fundamentais. Em primeiro lugar, porque emerge a criatividade e a margem de liberdade dos actores individuais no espaço-tempo da sua influência sobre os subsistemas grupais que integram a organização do trabalho do modelo universitário português. Em segundo lugar, porque, para permitir a coincidência do espaço-tempo virtual com o espaço-tempo real no contexto da organização do trabalho reportado à produção, à distribuição, ao consumo e à troca de bens e serviços analítico-simbólicos, é fundamental que os diferentes órgãos sensoriais cada actor - professor, aluno, professor - sejam a base substantiva das relações intrapessoais e interpessoais que corporizam todas as relações sociais entre chefes e subordinados ou entre líderes e liderados no processo de liderança.

A rigidez e o carácter prescrito do actual processo de liderança formal da organização do trabalho do modelo universitário português não é compatível com os objectivos de eficiência e de produtividade científica dos professores, alunos e funcionários. Já tínhamos sublinhado esses efeitos perversos aquando da análise da autoridade hierárquica formal que legitima e institucionaliza quem é líder formal e quem nunca o poderá ser. No caso dos professores, essas funções são corporizadas na figura emblemática do catedrático, nos funcionários com funções de topo da carreira administrativa, e no caso nos estudantes, essa hipótese não existe. 
Os problemas e os desafios que se apresentam para o processo de liderança formal não relevam exclusivamente das relações interpessoais, mas também da interacção sistemática e profunda destas com as relações intrapessoais. Na verdade, em termos intrapessoais, os estímulos e as respostas provenientes das contingências das TIC e da globalização atravessam de uma forma intensa e extensa todos os órgãos sensoriais de cada indivíduo que tenha a pretensão ou necessidade de evoluir como líder no espaço-tempo da organização do trabalho do modelo universitário português. Não obstante, a visão e a audição serem importantíssimas para esses efeitos, o tacto, o olfacto e o sabor não estão totalmente ausentes em qualquer processo de trabalho que envolva a influência de indivíduo sobre qualquer grupo ou subsistema universitário português.

Os conflitos entre a liderança formal versus a liderança informal generalizamse na organização do trabalho do modelo universitário português, e, em grande parte, esses conflitos resultam da incapacidade cognitiva, emocional e energética dos professores que exercem as funções de liderança. Os catedráticos vivem e reproduzem-se como líderes formais com base em qualificações e competências que tampouco servem como bases de adaptação e reacção aos modelos do passado, mas que estão completamente defasados da realidade actual. Como fenómeno espontâneo e informal de aprendizagem generalizada, os catedráticos, para hipoteticamente personificarem uma liderança de tipo informal e espontânea, têm que deixar de ser meros actores de transmissão de informação, conhecimento e energia, e transformarem-se em actores de aprendizagem conjuntamente com os alunos e funcionários. A emergência histórica deste tipo de liderança informal permite que a produção, a distribuição, a troca e o consumo de bens e serviços de características analítico-simbólicas se realizem de forma atempada e adequada. Nestas circunstâncias, poderão integrar os fluxos e as redes das TIC, e emergir com a sua cognição, emoção e energia na coincidência do espaço-tempo real com o espaço-tempo virtual no espaço-tempo da organização do trabalho do modelo universitário português. Esta hipótese é perfeitamente concebível para todas as categorias de professores universitários.

Por sua vez, o actual tempo histórico da simultaneidade e da instantaneidade das TIC e da globalização implica que os outros subsistemas da organização do trabalho do modelo universitário português possam também emergir como probabilidades de liderança informal efectiva. Neste aspecto, refiro-me concretamente a todos os indivíduos que integram o subsistema dos estudantes e dos funcionários. São tipos de liderança informal importantíssimos na medida em que só eles poderão superar os atavismos seculares da inexistência de uma aprendizagem efectiva no espaço-tempo da vida quotidiana dos estudantes, funcionários e professores que integram o sistema universitário português. 


\section{REFERÊENCIAS}

BAUMAN, Z. Globalização: as conseqüências humanas. Rio de Janeiro: Jorge Zahar, I999. Modernidade líquida. Rio de Janeiro: Jorge Zahar, 200 I.

BOLTANSKI, L.; CHIAPELLO, È. Le nouvel esprit du capitalisme. Paris: Gallimard, I999.

CASTELLS, M. La société en réseaux. Paris: Fayard, I998.

A era da informação: economia, sociedade e cultura. Lisboa: Fundação Calouste Gulbenkian, 2002. v. I.

A era da informação: economia, sociedade e cultura. Lisboa: Fundação Calouste Gulbenkian, 2003a. v. 2.

A era da informação: economia, sociedade e cultura. Lisboa: Fundação Calouste Gulbenkian, 2003b. v. 3 .

A galáxia da internet. Lisboa: Fundação Calouste Gulbenkian, 2004.

DUPAS, G. Economia global e exclusão social - pobreza, emprego, Estado e futuro do capitalismo. São Paulo: Paz e Terra, I999.

ELIAS, N. Sobre o tempo. Rio de Janeiro: Jorge Zahar, I998.

EME, B.; LAVILLE, J.-L. (Ed.). Cohésion sociale et emploi. Paris: Desclée de Drouwer, I994.

FEATHERSTONE, M. (Coord.). Cultura global - nacionalismo, globalização e modernidade. 2. ed. Petrópolis: Vozes, I998.

FERREIRA, J. M. C. Pedagogia e universidade no limiar do século XXI. Conselho Pedagógico. In: PRIMEIRAS JORNADAS PEDAGÓGICAS DO ISEG, I998. Lisboa: Iseg-UTL, I998a. p. 22-33.

Crise na universidade: problemas e tendências na formação e educação dos "recursos humanos”. Conselho Pedagógico. In: PRIMEIRAS JORNADAS PEDAGÓGICAS DO ISEG, I998. Lisboa: Iseg-UTL, I998b. p. I83-I97.

FERREIRA, J. M. C. Novas tecnologias e organização do trabalho. Episteme, n. 5/6, p. II9-I42, Outono/Inverno 2000.

Terceiro setor e limiares da autogestão. Verve, São Paulo, n. 8, p. 84-I20, 2005.

FERREIRA, J. M. C. et al. Manual de psicossociologia das organizações. Alfragide: McGraw-Hill, 200I.

GIBSON, W. Neuromante. Lisboa: Gradiva, 2004.

GOLDFINGER, C. Travail et hors-travail - vers une société fluide. Paris: Editions Odile Jacob, I998.

KERGOAT, J. et al. Le monde du travail. Paris: Editions La Découverte, I998.

LALLEMENT, M. (Ed.). Travail et emploi - les temps des métamorphoses. Paris: L'Harmattan, I994.

LEARY, T. Info-Psydiology. Las Vegas: Falcom Press, I990.

LUTTAK, E. Turbocapitalismo - vencedores e vencidos na economia global. Lisboa: Temas e Debates, 2000.

MUMFORD, L. Thécnique et civilisation. Paris: Fayard, I934.

Le mythe de la machine. Paris: Fayard, I974. 2 v.

NEVES, J. Personalidade, percepção e aprendizagem. In: FERREIRA, J. M. C. et al. Manual de psicossociologia das organizações. Alfragide: McGraw-Hill, 200I. p. 22I-254.

PARSONS, T. The Social System. Glencoe: The Free Press of Glencoe, I95I. 
PAUGAM, S. Le salarié de la précarité. Paris: PUF, 2000.

PINARD, R. La révolution du traval - de l'artisan au manager. Rennes: Presses Universitaires de Rennes, 2000.

ROBERTSON, R. Globalização - teoria social e cultura global. Petrópolis: Vozes, 2000.

SENNETT, R. A corrosão do carácter - consequências pessoais do trabalho no novo capitalismo. Lisboa: Terramar, 200 I.

SOROS, G. A crise do capitalismo global. Lisboa: Círculo de Leitores, I999.

SUPIOT, A. (Org.). Au-delà de l'emploi. Paris: Flamarion, I999.

WALLERSTEIN, I. The capitalist world-economy. Cambridge: Cambridge University Press, I979.

WATERS, M. Globalização. Oeiras: Celta, 2002. 